\title{
Identification of non-flagellar genes involved in swarm cell differentiation using a Bacillus thuringiensis mini-Tn10 mutant library \\ Correspondence \\ Emilia Ghelardi \\ ghelardi@biomed.unipi.it \\ Received 26 June 2008 \\ Revised 25 November 2008 \\ Accepted 25 November 2008 \\ Sara Salvetti, ${ }^{1}$ Francesco Celandroni, ${ }^{1}$ Mara Ceragioli, ${ }^{2}$ Sonia Senesi ${ }^{2}$ and Emilia Ghelardi ${ }^{1}$ \\ ${ }^{1}$ Dipartimento di Patologia Sperimentale, Biotecnologie Mediche, Infettivologia ed Epidemiologia, Università di Pisa, via San Zeno 35-39, 56127 Pisa, Italy \\ ${ }^{2}$ Dipartimento di Biologia, Sezione di Microbiologia, Università di Pisa, via San Zeno 35-39, 56127 Pisa, Italy \\ Swarming is a social phenomenon that enables motile bacteria to move co-ordinately over solid surfaces. The molecular basis regulating this process is not completely known and may vary among species. Insertional mutagenesis of a swarming-proficient Bacillus thuringiensis strain was performed, by use of the transposon mini-Tn10, to identify novel genetic determinants of swarming that are dispensable for flagellation, swimming motility, chemotaxis and active growth. Among the 67 non-swarming mutants obtained, six were selected that showed no defect in flagellar assembly and function, chemotaxis or growth rate. Sequence analysis of DNA flanking the transposon insertion led to the identification of previously uncharacterized genes that are involved in the development of swarming colonies by $B$. thuringiensis and that are highly conserved in all members of the Bacillus cereus sensu lato group. These genes encode non-flagellar proteins with putative activity as sarcosine oxidase, catalase-2, amino acid permease, ATP-binding cassette transporter, dGTP triphosphohydrolase and acetyltransferase. Functional analysis of two of the isolated mutants demonstrated that swarming differentiation depends on the intracellular levels of the osmoprotectant glycine betaine and on the quantity of synthesized phenazine secondary metabolites. The finding that proteins involved in diverse physiological processes have a role in swarming motility underlines the complexity of the molecular mechanisms governing this behaviour in $B$. thuringiensis.
}

\section{INTRODUCTION}

Swarming motility is a social form of surface locomotion that is exhibited by a wide variety of Gram-negative and Gram-positive bacteria (for a review see Harshey, 2003 and Kaiser, 2007). This co-operative behaviour allows organisms to actively spread on suitably moist surfaces in the environment or on mucosal surfaces in the infected host. In several species, the ability to swarm is accompanied by a complex differentiation process leading swimmer cells to produce long, polyploid, hyperflagellated swarm cells (Fraser \& Hughes, 1999; Harshey, 2003). These cells aggregate themselves in rafts and migrate over the surface in a highly co-ordinated manner that is dependent on multicellular interactions and cell-to-cell signalling (Rather, 2005). In swarming-proficient pathogens, swarm cells may exert a higher degree of virulence due to their enhanced ability to adhere to and colonize the host

Abbreviations: $\mathrm{AHL}, \mathrm{N}$-acylhomoserine lactone; $T_{\text {gen }}$ generation time; $\mathrm{Cl}$, chemotaxis index; $\mathrm{PZ}$, phenazine. mucosal surfaces (Allison et al., 1992a; Belas \& Colwell, 1982; Callegan et al., 2006; Kirov et al., 2004), as well as to secrete increased amounts of specific virulence factors (Allison et al., 1992b; Ghelardi et al., 2007; Macfarlane et al., 2001).

Genome- and proteome-scale studies highlighted that swarming differentiation requires a wide range of cellular functions (Kearns et al., 2004; Kim \& Surette, 2004; Wang et al., 2004). Nevertheless, the gene products specifically required for such a process are not completely known and may vary among species. Efficient assembly/function of flagella (Wang et al., 2006) and chemotaxis (Mariconda et al., 2006) are essential for swarm-cell differentiation in several swarming-proficient bacteria. In some species, biosynthesis of capsular polysaccharides, membrane lipopolysaccharides and biosurfactants plays a crucial role in promoting swarming or in facilitating bacterial migration across surfaces (for a review see Fraser \& Hughes, 1999). In addition, cell density appears to be a critical cue for swarming, as demonstrated by the dependence of 
swarm-cell differentiation on the quorum sensing mediated by extracellular $\mathrm{N}$-acylhomoserine lactones (AHLs) in many Gram-negative bacteria (Fraser \& Hughes, 1999).

We have previously described swarming motility in Bacillus cereus and Bacillus thuringiensis (Ghelardi et al., 2002; Senesi et al., 2002), two closely related bacterial species belonging to the B. cereus sensu lato complex (Rasko et al., 2005). In these species, swarming requires differentiation of swimmer cells into elongated and hyperflagellated swarm cells and is a relatively widespread behaviour of natural isolates (Ghelardi et al., 2007). In addition, the ability of these opportunistic human pathogens to swarm was proven to contribute to their pathogenicity, promoting invasive properties in vivo and leading to a notable increase in the secretion of virulence factors, in particular haemolysin BL (Callegan et al., 2006; Ghelardi et al., 2007; Senesi et al., 2002).

In $B$. cereus and $B$. thuringiensis functional flagella and molecular components involved in both flagellummediated motility and chemotactic response are essential for swarming (Ghelardi et al., 2002, 2007; Salvetti et al., 2007; Senesi et al., 2002). In this study, our aim was the identification of novel genes governing the transition from swimmer to swarm cells but dispensable for cell flagellation, motility, chemotaxis and active growth in $B$. thuringiensis.

\section{METHODS}

Bacterial strains, plasmids and growth conditions. The bacterial strains and plasmids used in this study are listed in Table 1. B. thuringiensis strain $407 \mathrm{Cry}^{-}$was used to produce the library of insertional mutants. Escherichia coli TOP10 was used as host for the construction of plasmids and cloning experiments and E. coli strain SCS110 for generating unmethylated plasmid DNA for B. thuringiensis transformation. B. thuringiensis strains were grown in tryptone$\mathrm{NaCl}$ broth $(\mathrm{TrB})(1 \%$ tryptone, $0.5 \% \mathrm{NaCl})$, brain heart infusion broth (BHI) or Luria-Bertani broth (LB) and usually incubated at $37{ }^{\circ} \mathrm{C}$. Media were routinely solidified with $1 \%$ agar unless otherwise specified. Glucose $(0.2 \%$, w/v) was added to the media when required. E. coli strains were grown in LB medium at $37^{\circ} \mathrm{C}$. Antibiotics used for bacterial selection included ampicillin $(100 \mu \mathrm{g}$ $\left.\mathrm{ml}^{-1}\right)$ or spectinomycin $\left(60 \mu \mathrm{g} \mathrm{ml}^{-1}\right)$ for $E$. coli and spectinomycin $\left(250 \mu \mathrm{g} \mathrm{m} \mathrm{m}^{-1}\right)$ or erythromycin $\left(25 \mu \mathrm{g} \mathrm{ml}^{-1}\right)$ for B. thuringiensis. Growth curves of $B$. thuringiensis strains were analysed in LB medium and the generation time $\left(T_{\text {gen }}\right)$ was calculated as follows: $T_{\text {gen }}=$ $t /[3.3 \log (b / B)]$, where $t$ is the time interval in minutes, $b$ the number of bacteria at the end of the time interval, and $B$ the number of bacteria at the beginning of the time interval. The biochemical profile of $B$. thuringiensis strains was determined by using the API $50-\mathrm{CHB}$ and API 20E strips tests (bioMérieux) accordingly to the manufacturer's instructions; test results were read after $24 \mathrm{~h}$ and $48 \mathrm{~h}$ with the ATB Plus software (bioMérieux).

Motility and chemotaxis assays. Phenotypic assays for swimming were performed on $\operatorname{TrB}$ fortified with $0.25 \%$ granulated agar $(\operatorname{TrM})$ and chemotaxis assays on TrM supplemented with $2 \mathrm{mM}$ mannitol, as previously described (Salvetti et al., 2007). Each chemotaxis assay was repeated three times on separate days and the chemotaxis index (CI) for each strain was calculated as follows: $\mathrm{CI}=\left(D_{\mathrm{a}}-D_{\mathrm{c}}\right) / D_{\mathrm{c}}$, where
$D_{\mathrm{a}}$ is the mean of growth halo diameters recorded on TrM plates supplemented with mannitol and $D_{\mathrm{c}}$ the mean of those measured in TrM without the attractant.

The ability to swarm was tested on BHI, LB, TrB and the same media supplemented with glucose (BHIG, LBG, TrBG) at various agar concentrations $(0.8 \%, 1.0 \%, 1.2 \%, 1.4 \%)$. Plates were centrally inoculated by spotting $0.5 \mu \mathrm{l}$ of an overnight culture (approx. $2 \times 10^{8}$ cells $\mathrm{ml}^{-1}$ ) and incubated at $37^{\circ} \mathrm{C}$ in a humidified chamber. The swarming patterns and the presence of differentiated swarm cells were evaluated at $6,12,18,24$ and 48 h post-inoculation. Formation of swarm cells was assessed by analysing cell length and the amount of cell-surface flagella, by phase-contrast microscopy of bacteria stained with a solution containing $10 \%(\mathrm{w} / \mathrm{v})$ crystal violet (Salvetti et al., 2007) or flagellar staining for light microscopy (Harshey \& Matsuyama, 1994), respectively.

Mutagenesis. Transposition of the mini- $\operatorname{Tn} 10$ into the $B$. thuringiensis $407 \mathrm{Cry}^{-}$genome was performed using the thermosensitive plasmid pIC333 (Steinmetz \& Richter, 1994) as a delivery vector. About $1 \mu \mathrm{g}$ of pIC333 was used to transform strain 407 Cry $^{-}$by electroporation. Transformants were selected at $28{ }^{\circ} \mathrm{C}$ on LB plates containing both spectinomycin and erythromycin. Antibiotic-resistant clones were pooled and cultured at $28{ }^{\circ} \mathrm{C}$ in LB broth containing spectinomycin for $3 \mathrm{~h}$. Cells were diluted $(1: 100)$ and grown in LB broth at $40{ }^{\circ} \mathrm{C}$ (non-permissive temperature for the replication of the plasmid) for 15 generations. Appropriate dilutions of the culture were then spread on LB agar containing spectinomycin and incubated overnight at $37{ }^{\circ} \mathrm{C}$. Following growth, bacteria were analysed for resistance to erythromycin; only erythromycin-sensitive clones were collected to produce the library of insertional mutants.

Identifying sites of transposon insertion. To identify the region of mini-Tn 10 insertion, chromosomal DNA was extracted from selected mutants, as previously described (Senesi et al., 2002), digested with EcoRI or HindIII (restriction sites for these enzymes are not present in the mini-Tn 10) and subjected to ligation. As the mini-Tn 10 contains an E. coli origin of replication, the ligation mixture was used to transform E. coli strain TOP10, and spectinomycin-resistant clones were selected. Plasmid DNA was extracted from the E. coli transformants by the NucleoSpin Plasmid Purification kit (Machery-Nagel) and sequenced using primers E1 and E3 (Table 2), matching the ends of the mini-Tn10, as described by Gominet et al. (2001). DNA sequencing was performed by the ALFexpress AutoRead Sequencing kit (Pharmacia Biotech) in the ALFexpress DNA sequencer (Pharmacia) and all ORFs longer than $100 \mathrm{bp}$ were examined.

Southern blot analysis was performed as described elsewhere (Senesi et al., 2002), using Hybond-NX membranes (Amersham Biosciences) and ${ }^{32} \mathrm{P}$-dCTP-labelled DNA probes.

Sequence analysis. The DNA sequences surrounding the sites of mini- $\operatorname{Tn} 10$ insertion were analysed by using the software PathemaBacillus (http://pathema.jcvi.org/cgi-bin/Bacillus/PathemaHomePage. cgi). This resource was chosen since it contains an in-depth curatorial analysis of micro-organisms belonging to the B. cereus group and offers single-genome and comparative multi-genome analysis for these bacteria. The deduced amino acid sequences were compared against all Bacillus peptide files running wU-BLAST 2.0 available in Pathema-Bacillus or analysed in the GenBank, EMBL and Swiss-Prot databases by using the BLASTX, BLASTP or PSI-BLAST network service at the National Center for Biotechnology Information (NCBI) (Altschul et al., 1997). To predict the presence of transmembrane helices and topology of putative proteins, the amino acid sequences were analysed using the programs TMpred and PredictProgram at the ExPASy proteomics server of the Swiss Institute of Bioinformatics (http:// expasy.org). 
Table 1. Bacterial strains and plasmids used in this study

\begin{tabular}{|c|c|c|}
\hline Strain or plasmid & Genotype or characteristic & Source or reference \\
\hline \multicolumn{3}{|l|}{$\begin{array}{l}\text { Bacillus } \\
\text { thuringiensis }\end{array}$} \\
\hline 407 Cry $^{-}$ & Swarming-proficient wild-type strain & Lereclus et al. (1989) \\
\hline MP10 & Swarming-defective derivative of $407 \mathrm{Cry}^{-}$ & This study \\
\hline MP11 & Swarming-defective derivative of $407 \mathrm{Cry}^{-}$ & This study \\
\hline MP12 & Swarming-defective derivative of $407 \mathrm{Cry}^{-}$ & This study \\
\hline MP13 & Swarming-defective derivative of $407 \mathrm{Cry}^{-}$ & This study \\
\hline MP14 & Swarming-defective derivative of $407 \mathrm{Cry}^{-}$ & This study \\
\hline MP15 & Swarming-defective derivative of $407 \mathrm{Cry}^{-}$ & This study \\
\hline MP16 & Derivative of MP10, containing pHT2787 & This study \\
\hline MP17 & Derivative of MP11, containing pHT2969 & This study \\
\hline MP18 & Derivative of MP12, containing pHT0713 & This study \\
\hline MP19 & Derivative of MP13, containing pHT3576 & This study \\
\hline MP20 & Derivative of MP14, containing pHT5364 & This study \\
\hline MP21 & Derivative of MP15, containing pHT3423 & This study \\
\hline MP22 & Derivative of MP15, containing pHT3423-3422 & This study \\
\hline \multicolumn{3}{|l|}{ Escherichia coli } \\
\hline SCS110 & $\begin{array}{l}\text { rpsL }\left(\mathrm{Str}^{\mathrm{r}}\right) \text { thr leu endA thi-1 lacY galK galT ara tonA tsx dam dcm supE44 } \Delta \text { (lac-proAB) } \\
{\left[\mathrm{F}^{\prime} \text { traD36 proAB lacl }{ }^{\mathrm{q}} Z \Delta \mathrm{M} 15\right]}\end{array}$ & Stratagene \\
\hline TOP10 & $\begin{array}{l}\mathrm{F}^{-} \text {mcrA } \Delta(\text { mrr-hsdRMS-mcrBC) } \phi 80 \text { lacZ } \Delta \mathrm{M} 15 \Delta \text { lacX74 deoR recA1 endA1 ara } \Delta 139 \\
\Delta(\text { ara, leu }) 7697 \text { galU galK } \lambda^{-} \text {rpsL }\left(\mathrm{Str}^{\mathrm{r}}\right) \text { nupG }\end{array}$ & Invitrogen \\
\hline \multicolumn{3}{|l|}{ Plasmids } \\
\hline pIC333 & $\begin{array}{l}\text { Thermosensitive Gram-positive origin of replication; } 2.4 \mathrm{~kb} \text { mini- } \mathrm{Tn} 10 \text { containing a } \\
\text { ColE1 origin of replication and an } \mathrm{Spc}^{\mathrm{r}} \text { gene; } \operatorname{Tn} 10 \text { transposase gene; } \mathrm{Em}^{\mathrm{r}}\end{array}$ & $\begin{array}{l}\text { Steinmetz \& Richter } \\
\text { (1994) }\end{array}$ \\
\hline pHT304 & Expression vector with $l a c Z$ promoter; Gram-positive origin of replication, ori E. coli; $\mathrm{Em}^{\mathrm{r}} \mathrm{Ap}^{\mathrm{r}}$ & $\begin{array}{l}\text { Arantes \& Lereclus } \\
(1991)\end{array}$ \\
\hline pHT2787 & Derivative of pHT304, containing the BT2787 gene amplified from B. thuringiensis $407 \mathrm{Cry}^{-}$ & This study \\
\hline pHT2969 & Derivative of pHT304, containing the BT2969 gene amplified from B. thuringiensis $407 \mathrm{Cry}^{-}$ & This study \\
\hline pHT0713 & Derivative of pHT304, containing the BT0713 gene amplified from B. thuringiensis $407 \mathrm{Cry}^{-}$ & This study \\
\hline pHT3576 & Derivative of pHT304, containing the BT3576 gene amplified from $B$. thuringiensis 407 Cry $^{-}$ & This study \\
\hline pHT5364 & Derivative of pHT304, containing the BT5364 gene amplified from B. thuringiensis 407 Cry $^{-}$ & This study \\
\hline pHT3423 & Derivative of pHT304, containing the BT3423 gene amplified from B. thuringiensis 407 Cry $^{-}$ & This study \\
\hline pHT3423-3422 & $\begin{array}{l}\text { Derivative of pHT304, containing the BT3423/BT3422 gene region amplified from } \\
\text { B. thuringiensis } 407 \text { Cry }^{-} \text {with the primer pair BT3423U/BT3422L }\end{array}$ & This study \\
\hline
\end{tabular}

Complementation. For complementation experiments, the genes disrupted by the transposon were amplified by PCR from $B$. thuringiensis $407 \mathrm{Cry}^{-}$by using primers designed on the basis of $B$. thuringiensis konkukian DNA sequence (Table 2). Each PCR product was purified, digested (for the restriction enzyme used, see Table 2), and ligated into the expression vector pHT304 (Arantes \& Lereclus, 1991). The mini-Tn 10 mutants were transformed with the recombinant plasmids (Table 1) and selected for erythromycin resistance.

Sarcosine oxidase activity. Sarcosine oxidase activity was assayed in crude extracts of bacterial cultures that were normalized to the same $\mathrm{OD}_{600}$, as described by Koyama et al. (1991), using $0.2 \mathrm{M}$

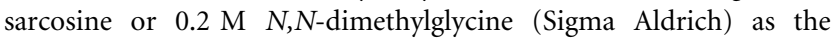
substrate. Each reaction mixture was incubated at $37^{\circ} \mathrm{C}$ for $10 \mathrm{~min}$. One unit $(\mathrm{U})$ of the enzyme was defined as the amount of enzyme which liberated $1 \mu \mathrm{mol}$ formaldehyde per minute.

Phenazine quantification. Phenazines (PZs) were quantified essentially as described by Maddula et al. (2008). Briefly, bacteria were grown in $5 \mathrm{ml} \mathrm{BHIG}$ broth at $30{ }^{\circ} \mathrm{C}$ to the late-exponential phase and cell-free culture supernatants were acidified to $\mathrm{pH} 2$ with concentrated $\mathrm{HCl}$. Total PZs were extracted with benzene, dissolved in $0.1 \mathrm{M} \mathrm{NaOH}$, quantified via absorbance at $367 \mathrm{~nm}$ and expressed as $A_{367}$ for $10^{10}$ bacterial cells. PZs were also quantified after growth under swarming condition by growing bacteria on Anopore membranes $(0.2 \mu \mathrm{m}$ pore size) of $10 \mathrm{~mm}$ cell culture inserts (Nalge Nunc International) in BHIG as previously described (Ghelardi et al., 2007). After $48 \mathrm{~h}$ incubation at $30{ }^{\circ} \mathrm{C}$, the number of c.f.u. on the membranes was counted, and PZs were quantified as described above.

Statistical analysis. Statistical analysis was performed using the GraphPad InStat Software. A $P$-value $<0.05$ was considered statistically significant. Values were expressed as the mean \pm SD from five independent experiments.

\section{RESULTS AND DISCUSSION}

\section{Phenotype of B. thuringiensis $407 \mathrm{Cry}^{-}$swarming colonies on different solid media}

Swarming in Bacillus spp. is a recently described phenomenon. In these species, swarming motility occurs on rich media at a wide range of agar concentrations and temperatures (Ghelardi et al., 2002; Senesi et al., 2002, 
Table 2. Primers used for PCR amplification

\begin{tabular}{|c|c|c|c|}
\hline Primer & Sequence $\left(5^{\prime}-3^{\prime}\right)^{*}$ & Target/base pair coordinates $\dagger$ & Restriction site \\
\hline BT2787U & GATAAGCTTATAATACACTT & BT2787, from -145 to -125 & HindIII \\
\hline BT2787L & TCCGGATCCTACATCATGAC & BT2787, from +1364 to +1344 & BamHI \\
\hline BT2969L & ATT $\overline{\text { GGATCCGTTGCAATG }}$ & BT2969, from +1570 to +1552 & BamHI \\
\hline ВT0713U & CGTCTGCAGTTTTACAGA & BT0713, from -71 to -53 & Pst $\mathrm{I}$ \\
\hline BT0713L & GATGGATCCTTTTAGTTG & BT0713, from +1731 to +1713 & BamHI \\
\hline BT3576L & TTAGCATGCGAAACGGA & BT3576, from +1850 to +1833 & SphI \\
\hline BT5364U & AGCAAGCTTTCACTTT & BT5364, from -141 to -125 & HindIII \\
\hline BT5364L & AAGCTGCAGAACTGGTGC & BT5364, from +1447 to +1429 & Pst $\mathrm{I}$ \\
\hline BT3423U & TGAAAGCTTCTGAAGGAG & BT3423, from -103 to -85 & HindIII \\
\hline BT3423L & TATGGATCCTACTTCTGA & BT3423, from +965 to +947 & BamHI \\
\hline BT3422L & TTT $\overline{\text { GGATCCCGCTATTCG }}$ & BT3422, from +984 to +966 & BamHI \\
\hline
\end{tabular}

${ }^{\star}$ Restriction site is underlined.

$\dagger$ Numbers refer to nucleotide position in the indicated gene, relative to the putative translational initiation site.

2004). Nevertheless, the possibility of predicting swarming differentiation by measuring colony diameter or observing the colony appearance was proven to be inapplicable for strains belonging to the $B$. cereus sensu lato group (Ghelardi et al., 2007; Hsueh et al., 2007). The ability to swarm by $B$. cereus and $B$. thuringiensis can only be ascertained by visualizing the presence of elongated and hyperflagellated cells inside the developing colony (Ghelardi et al., 2002; Senesi et al., 2002). To facilitate the screening of swarmingdefective derivatives of strain $407 \mathrm{Cry}^{-}$, the wild-type strain was inoculated on a variety of rich media (BHI, BHIG, LB, LBG, TrB, TrBG) containing different agar concentrations $(0.8 \% ; 1.0 \% ; 1.2 \% ; 1.4 \%)$ and analysed for colony type and swarm cells after incubation at $37^{\circ} \mathrm{C}$ for $6,12,18,24$ and $48 \mathrm{~h}$. Long and extensively flagellated swarm cells were visualized after growth on all tested media at the different time points examined (data not shown). However, the colony produced on BHIG fortified with $1.4 \%$ granulated agar after $48 \mathrm{~h}$ was the widest we obtained and was characterized by concentric rings due to alternate cycles of swarming migration and consolidation phases (Fig. 1), as described for swarming by Proteus mirabilis (Douglas \& Bisset, 1976). Therefore, this culture condition was chosen and applied throughout the study for the screening of swarming-defective mutants of strain 407 Cry ${ }^{-}$.

\section{Production, isolation and characterization of non-swarming mutants}

With the aim of identifying genes required for swarming by B. thuringiensis, insertional mutagenesis of strain $407 \mathrm{Cry}^{-}$ was carried out using the transposon mini-Tn 10. Approximately 5000 spectinomycin-resistant and erythromycin-sensitive mutants were isolated and screened for swarming defects. On inspection of the mutant library, 67 strains generated a colony that was clearly different from that produced by the wild-type. All these strains exhibited partially reduced colony spreading and lacked the characteristic colony organization in concentric rings. Each of the 67 selected strains was analysed for swimming motility on TrM in comparison with strain $407 \mathrm{Cry}^{-}$, to exclude all the mutants showing swimming defects. Twenty-eight strains did not generate any migration halo (data not shown); the high number of mutants displaying a defective swimming phenotype probably reflected the high number of genes required for flagella assembly and/or functionality in which the transposon insertion could have occurred. Among the remaining mutants $(n=39), 14$ showed growth defects in liquid medium (prolonged lag phase and/or increased generation time) and were not analysed further. Swimming-proficient and normally growing strains $(n=25)$ were inoculated on TrM plates containing mannitol to evaluate their ability to undergo chemotaxis. Since the CI value of strain $407 \mathrm{Cry}^{-}$was 0.94, all strains displaying CI values lower than 0.5 were excluded from the study. On the basis of the CI value of each mutant, eight strains were selected that did not show evident chemotactic defects. To evaluate whether the transposon insertion caused metabolic alterations, the biochemical profile of each mutant was analysed. No difference was found in the ability to use carbohydrates or amino acids for growth by using the API 50-CHB and API 20E strip tests.

Among the eight mutants, some strains were subsequently demonstrated to contain identical transposon insertions and hence were likely to be siblings. Leaving these aside, our mutant collection consisted of six strains which showed: (I) overlapping growth curves $\left(T_{\text {gen }}\right.$ ranging from $22.06 \pm 2.4$ to $27.91 \pm 2.8 \mathrm{~min}$ ) and biochemical profile; 

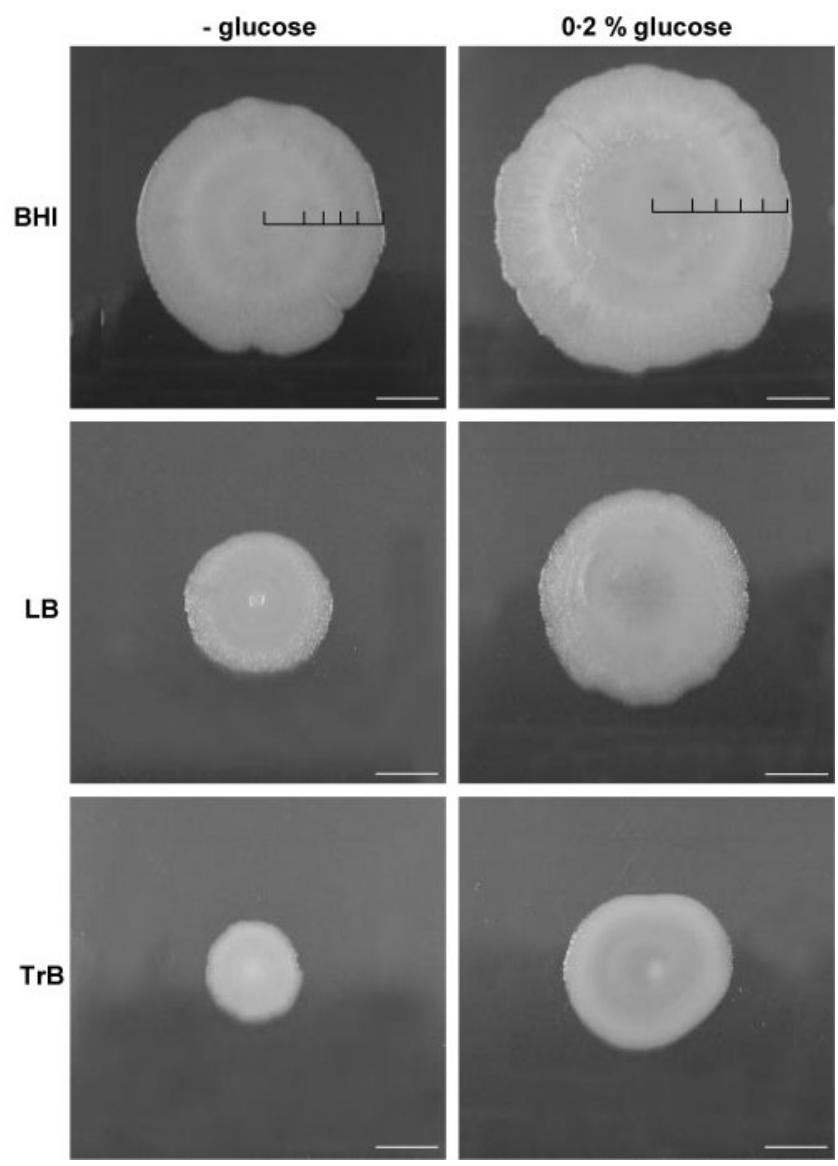

Fig. 1. Phenotype of $B$. thuringiensis $407 \mathrm{Cry}^{-}$swarming colonies on different media. The strain was centrally inoculated on BHI, LB, and TrB fortified with $1.4 \%$ granulated agar with or without $0.2 \%$ glucose. After $48 \mathrm{~h}$ incubation at $37{ }^{\circ} \mathrm{C}$, plates were photographed against a black background. Black bars in the upper images indicate the concentric rings inside the swarming colony. White scale bars indicate $1 \mathrm{~cm}$.
(II) similar proficiency for swimming motility and chemotaxis (Table 3 ); and (III) similar colony morphotype on BHIG fortified with $1.4 \%$ agar, but remarkably different from that developed by the wild-type strain (Fig. 2). Finally, the colonies produced by the selected mutants were analysed for the presence of differentiated swarm cells. None of the strains were able to produce hyperflagellated and elongated cells, and only oligoflagellated swimmer cells were viewed during colony development (Table 3, Fig. 2).

\section{Identification of the genes disrupted in the non- swarming mutants}

As no HindIII or EcoRI restriction sites are present in the mini-Tn10, the six swarming-defective mutants were analysed for the presence of the transposon by Southern hybridization of HindIII or EcoRI chromosomal DNA digestions. A single reactive band was detected for all strains, indicating that each mutant carried a single genomic insertion (data not shown). The DNA flanking the transposon was isolated and cloned into E. coli (see Methods) and the recombinant plasmids were used as templates to determine the nucleotide sequence of the chromosomal DNA adjacent to the mini-Tn 10 insertion site. The mini-Tn 10 generates a 9 bp duplication at the site of insertion, which served as a tag to identify the disrupted gene (Table 4).

The sequences obtained for each strain were submitted to the Pathema-Bacillus software; the nomenclature of $B$. thuringiensis konkukian genes was adopted to indicate the interrupted genes, as no complete chromosomal sequence is available for strain $407 \mathrm{Cry}^{-}$of B. thuringiensis (Table 4). This search revealed that the transposon had inactivated non-flagellar genes highly conserved in all completely sequenced members of the B. cereus sensu lato group. Fig. 3 shows the gene organization of the regions comprising the disrupted genes on the B. thuringiensis konkukian genome. The polar effects of the mini-Tn 10 insertion were evaluated

Table 3. Motility of $B$. thuringiensis strains in liquid and solid environment

\begin{tabular}{|c|c|c|c|c|c|c|}
\hline \multirow[t]{2}{*}{ Strain } & \multicolumn{3}{|c|}{ Liquid environment } & \multicolumn{3}{|c|}{ Solid surface } \\
\hline & MOT $^{*}$ & $\mathrm{CI} \dagger$ & Max. cell length $(\mu \mathrm{m})$ & Hyper-FLA $\ddagger$ & Max. cell length $(\mu \mathrm{m})$ & SW\$ \\
\hline $407 \mathrm{Cry}^{-}$ & + & 0.94 & 4.0 & + & 13.2 & + \\
\hline MP10 & + & 0.78 & 4.0 & - & 6.0 & - \\
\hline MP11 & + & 0.66 & 3.8 & - & 5.1 & - \\
\hline MP12 & + & 0.85 & 4.1 & - & 4.0 & - \\
\hline MP13 & + & 1.20 & 4.0 & - & 5.9 & - \\
\hline MP14 & + & 1.40 & 3.9 & - & 4.0 & - \\
\hline MP15 & + & 1.00 & 4.0 & - & 4.2 & - \\
\hline
\end{tabular}

${ }^{\star}$ Swimming motility was evaluated on tryptone- $\mathrm{NaCl}$ plates containing $0.25 \%$ agar ( $\mathrm{TrM}$ ).

$\dagger$ Chemotaxis index was calculated as described in Methods.

$\ddagger$ Cell hyperflagellation was defined as a $>3$-fold increase in flagellation from liquid to solid medium.

$\S$ Swarming motility was evaluated by the presence of hyperflagellated and elongated cells. 

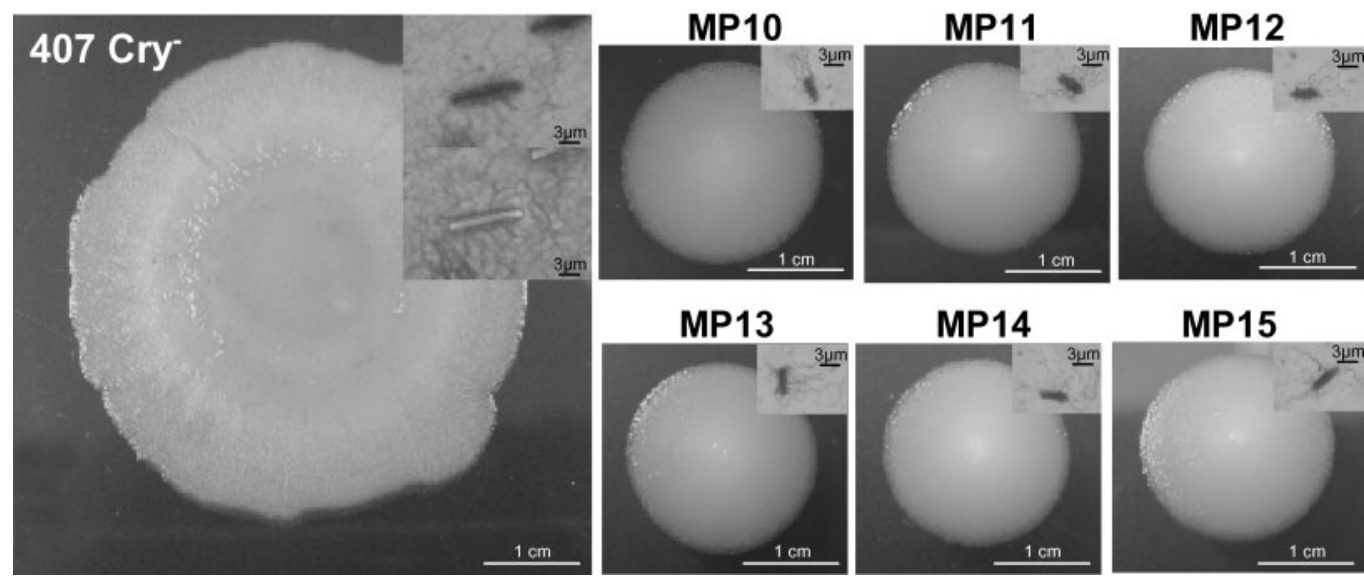

MP15

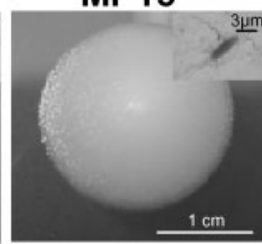

Fig. 2. Analysis of swarming behaviour of $B$. thuringiensis strains. B. thuringiensis $407 \mathrm{Cry}^{-}$and its derivative mutants were centrally inoculated on BHIG fortified with $1.4 \%$ granulated agar and incubated for $48 \mathrm{~h}$ at $37^{\circ} \mathrm{C}$. Insets show the phenotype of cells collected from the colony rim.

by introducing into each mutant a wild-type copy of the interrupted gene by the plasmid pHT304, thus producing strains MP16-MP21 (Table 1). Only strain MP21 did not restore a swarming phenotype, thus indicating that transposition Tn $\Omega 4245$ could generate polar effects on the expression of the downstream gene (Table 4, Fig. 3).

\section{BT2787 encodes monomeric sarcosine oxidase}

The transposition Tn $\Omega 63$ occurred in a BT2787 homologous gene. BT2787 had not been previously characterized in the genus Bacillus. However, it is predicted to encode the monomeric form (EC 1.5.99.2) or the beta subunit (EC 1.5.99.1) of multimeric sarcosine oxidase, which are involved in the glycine-betaine degradation pathway and show strong sequence similarity (Chen et al., 2006). Monomeric sarcosine oxidase catalyses the oxidation of $\mathrm{N}, \mathrm{N}$-dimethylglycine into sarcosine ( $N$-methylglycine), which is converted into glycine by the multimeric enzyme. Oxidation of both substrates generates formaldehyde, whose production is used to quantify the enzyme activity. To establish which enzyme was defective in strain MP10, the enzyme activity was assayed in bacterial crude extracts using sarcosine or $N, N$-dimethylglycine as the substrate. No defect in the conversion of sarcosine into glycine was found, the enzyme activity being $0.28 \pm 0.07$ and $0.34 \pm 0.06 \mathrm{U} \mathrm{ml}^{-1}$ for the mutant and the wild-type strain, respectively $(P=0.18)$. This result suggested that the mini-Tn 10 insertion had occurred in the gene encoding the monomeric form of sarcosine oxidase. Indeed, this enzymic activity was only found in strain B. thuringiensis $407 \mathrm{Cry}^{-}\left(0.030 \pm 0.006 \mathrm{U} \mathrm{ml}^{-1}\right)$ and no formaldehyde was ever generated by the mutant crude extract using $N, N$ dimethylglycine as the substrate. Since high levels of intracellular glycine betaine are obtained by inhibition of the enzymes involved in its degradation pathway (Lucht \& Bremer, 1994; Smith et al., 1988), the mutation in BT2787 could lead to an increase in the cytoplasmic levels of this compound. Glycine betaine is a very efficient osmolyte that accumulates intracellularly in response to sudden increases

Table 4. Transposon insertion sites that abolish swarming differentiation

\begin{tabular}{|c|c|c|c|c|c|c|}
\hline Strain & $\begin{array}{l}\text { Transposon } \\
\text { insertion }\end{array}$ & $\begin{array}{l}\text { Transposon } \\
\text { insertion site }\end{array}$ & $\begin{array}{c}\text { Polar effect of } \\
\text { transposon insertion }\end{array}$ & $\begin{array}{c}\text { Homologous } \\
\text { gene } \dagger\end{array}$ & $\begin{array}{c}\text { Identity } \\
(\%) \ddagger\end{array}$ & Putative function \\
\hline MP10 & $\operatorname{Tn} \Omega 63$ & GGTTGCGCT & No & BT2787 & 86 & Sarcosine oxidase \\
\hline MP11 & $\operatorname{Tn} \Omega 940$ & TACGAAGTT & No & BT2969 & 87 & Catalase-2 \\
\hline MP12 & $\operatorname{Tn} \Omega 962$ & CATTAAGCT & No & BT0713 & 83 & Amino acid permease \\
\hline MP13 & $\operatorname{Tn} \Omega 1851$ & TGCTGAGTA & No & BT3576 & 86 & $\begin{array}{l}\text { ABC transporter, substrate- } \\
\text { binding protein }\end{array}$ \\
\hline MP14 & $\operatorname{Tn} \Omega 4040$ & GATCAAGTA & No & BT5364 & 90 & dGTP triphosphohydrolase \\
\hline MP15 & $\operatorname{Tn} \Omega 4245$ & TACTTGGAT & Yes & BT3423 & 90 & Acetyltransferase \\
\hline
\end{tabular}

*Deduced by trans-complementation experiments performed as described in Methods.

$\dagger$ Nomenclature of the homologous genes in B. thuringiensis konkukian.

$\ddagger$ Percentage similarity values of the $B$. thuringiensis $407 \mathrm{Cry}^{-}$ORFs to those of B. thuringiensis konkukian. 
(a)

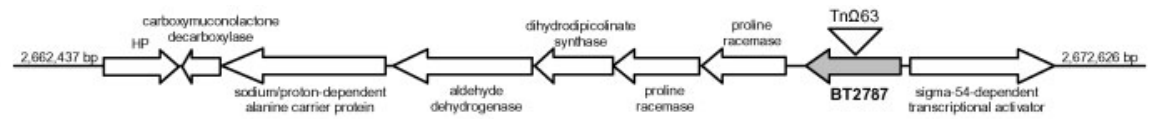

(b)

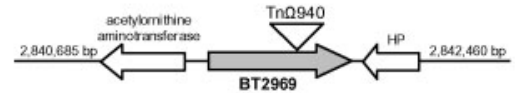

(c)

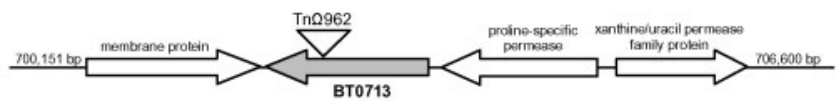

(d)

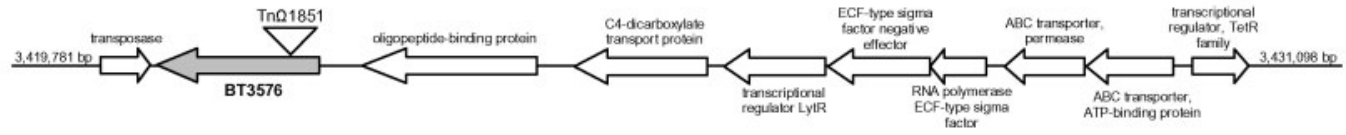

(e)

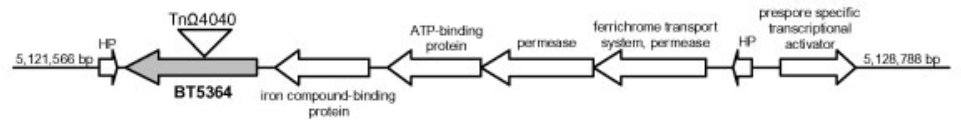

(f)

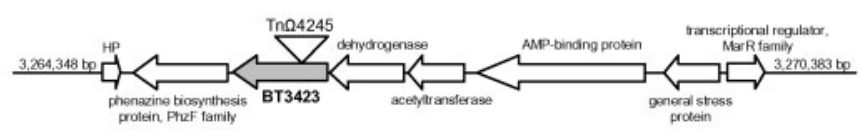

Fig. 3. Chromosome maps of $B$. thuringiensis konkukian indicating sites of transposon insertions that impaired swarming in $B$. thuringiensis $407 \mathrm{Cry}^{-}$. (a) MP10; (b) MP11; (c) MP12; (d) MP13; (e) MP14; (f) MP15. Coding regions are represented as horizontal arrows. Each insertional mutation is represented by an inverted triangle bearing the number of its corresponding $B$. thuringiensis $407 \mathrm{Cry}^{-}$mutant.

in the osmolarity of the growth medium, to act as an osmoprotectant (Østerås et al., 1998). Intracellular levels of glycine betaine are finely tuned to maintain the adequate cellular turgor essential for DNA replication and cell growth (Meury, 1988). It has been extensively demonstrated that a high osmolarity of the medium has an inhibitory effect on swarming motility (Liu et al., 2000; Shin \& Park, 1995; Young et al., 1999). Therefore, the abnormal accumulation of glycine betaine in strain MP10 could mimic the physiological state that the cell acquires in high-osmolarity environments, thus impairing swarming motility.

\section{BT2969, a gene putatively encoding catalase-2}

The gene interrupted by the mini-Tn10 in strain MP11 encodes a protein showing sequence similarity $(37 \%$ identity, $55 \%$ positivity) to B. subtilis KatE. In B. subtilis and E. coli, the katE gene encodes catalase-2 (hydroperoxidase II), which is not essential for active growth but is required for coping with cellular stress or adverse growth conditions, such as nutrient depletion or high cell density (Engelmann et al., 1995; Von Ossowski et al., 1991, Weber et al., 2006). Although the role of catalase-2 in swarming differentiation by $B$. thuringiensis is not clear, we can suggest that this enzyme is needed when vegetative cells reach the high cell density required for swarming induction. This hypothesis is also supported by the finding that the catB gene of Streptomyces coelicolor, homologous to $k a t E$, is essential for morphological differentiation of this organism on solid cultures (Cho et al., 2000).

\section{BT0713, a gene encoding a putative cryptic amino acid permease}

The transposition $\operatorname{Tn} \Omega 962$ inactivated a gene that encodes a hydrophobic integral membrane protein that may function as a cryptic amino acid permease. Since amino acids act as inducers of swarming differentiation in many microorganisms (Dick et al., 1985; Köhler et al., 2000) and the amino acid permease encoded by BT0713 is dispensable for vegetative growth in B. thuringiensis $407 \mathrm{Cry}^{-}$, it can be supposed that such a cryptic permease is a possible sensory route for sensing extracellular signals that promote swarm cell differentiation by $B$. thuringiensis.

\section{BT3576, a gene that encodes a putative ATP- binding cassette transporter component}

Strain MP13 harbours the mini-Tn10 insertion in a BT3576 homologous gene. As noted following TMpred analysis, the amino acid sequence encoded by BT3576 contains a putative transmembrane helix at its $\mathrm{N}$-terminus and a large C-terminal domain outside the cell. Analysis of the BT3576 predicted amino acid sequence revealed homology with the substrate-binding protein of a variety of ATP-binding cassette $(\mathrm{ABC})$ transporters in many different organisms. Although further studies are required 
to elucidate the role of BT3576 in swarming, the finding that the transposition $\mathrm{Tn} \Omega 1851$ produces a non-swarming phenotype suggests that the BT3576-encoded protein is part of a sensory system involved in the development of the highly organized $B$. thuringiensis swarming community.

\section{BT5364, a gene predicted to encode a phosphohydrolase}

The amino acid sequence deduced by BT5364, the gene disrupted in strain MP14, contains an HD sequence motif characteristic of metal-dependent phosphohydrolases. The family of HD phosphatases that have been analysed at the biochemical level are involved in a variety of biological processes, such as nucleic acid metabolism and signal transduction (Aravind \& Koonin, 1998). Lack of additional conserved domains and the position of the HD domain inside the predicted protein encoded by BT5364 suggest its function as dGTPase. In E. coli, this enzyme is not essential for viability and is involved in purine breakdown under conditions of purine excess, such as those occurring transiently when cells approach the stationary phase (Kim et al., 2006; Wurgler \& Richardson, 1993). Whatever the role of the protein encoded by BT5364, it will be of interest to determine how abrogation of this function leads to lack of swarming development in $B$. thuringiensis.

\section{MP15 shows defects in the production of phenazine compounds}

Strain MP15 harbours the mini-Tn10 insertion in a gene that is homologous to the BT3423 gene of B. thuringiensis konkukian and potentially encodes an acetyltransferase (Table 4). As mentioned above, transposition Tn 24245 could cause polar effects on the expression of the downstream gene BT3422 (Fig. 3). To assess this possibility, MP15 was transformed with pHT3423-3422 (Table 1), a plasmid carrying BT3422 and BT3423. The resulting strain (MP22) regained the ability to swarm, thus suggesting that the activity of both genes is required for swarming motility by $B$. thuringiensis. BT3422 is predicted to encode a phenazine biosynthesis protein of the $p h z F$ family. In Pseudomonas spp., the PhzF proteins are involved in the production of $\mathrm{PZ}$ derivative antibiotic and antifungal compounds (for a review see Chin-AWoeng et al., 2003). In P. aeruginosa, the production of the $\mathrm{PZ}$ compound pyocyanin is dependent on the AHL system (Chugani et al., 2001), which also regulates swarming motility in this organism (Reimmann et al., 2002). Furthermore, the expression in $P$. aeruginosa of the $B$. thuringiensis gene aiiA, encoding an AHL-lactonase, leads to a decrease in pyocyanin synthesis, as well as in swarming motility (Wang et al., 2007). More recently, an alteration in the ratio of PZs was associated with defects in the production of the surface multicellular communities constituting biofilms in Pseudomonas chlororaphis (Maddula et al., 2008). To assess whether MP15 was defective in the production of $\mathrm{PZ}$ compounds compared to the wild-type strain, total PZs were quantified in the supernatants of late-exponential-phase cultures of both strains. The mutant showed a 3.8 -fold reduction in the amount of total PZs secreted, the $A_{367}$ for $10^{10}$ cells being $0.85 \pm 0.16$ and $3.22 \pm 0.34$ for MP15 and $B$. thuringiensis $407 \mathrm{Cry}^{-}$, respectively $(P<0.001)$. PZs were also quantified for both strains during growth under conditions that induced swarming in the wild-type strain. MP15 showed a reduction in the production of these compounds in such culture conditions also, the $A_{367}$ for $10^{10}$ cells being $4.43 \pm 0.91$ vs $7.35 \pm 1.76(P=0.011)$.

Although little is known yet regarding the physiological function of $\mathrm{PZs}$ in their natural environment, it is becoming clear that these compounds can act as secondary metabolites able to regulate global gene expression patterns (for a review see Price-Whelan et al., 2006). The finding that an altered production of PZs is associated with the inability of $B$. thuringiensis to produce swarming colonies suggests that these molecules may serve as signals inducing gene expression changes required for differentiation into long and hyperflagellated swarm cells. It is expected that substantial additional work will be required to elucidate the biosynthetic pathways of PZs in B. thuringiensis and the exact mechanism by which PZs regulate the development of $B$. thuringiensis multicellular communities.

\section{Conclusions}

We have identified six previously uncharacterized $B$. thuringiensis genes that are required for swarming, but dispensable for flagellation, swimming, chemotaxis and active growth. The finding that these proteins appear to be involved in several and diverse cellular functions highlights the complex scenario of molecular components governing swarming by $B$. thuringiensis. Further studies are required to better elucidate the role of the identified genes in allowing swimmer cells to enter a swarm-cell state.

\section{ACKNOWLEDGEMENTS}

This work was supported by a research grant from Italian 'Ministero dell'Istruzione, dell'Università e della Ricerca', under contract no. 2005058814.

\section{REFERENCES}

Allison, C., Jones, P., Coleman, N. \& Hughes, C. (1992a). Ability of Proteus mirabilis to invade human urothelial cells is coupled to motility and swarming differentiation. Infect Immun 60, 4740-4746.

Allison, C., Lai, H. C. \& Hughes, C. (1992b). Co-ordinate expression of virulence genes during swarm-cell differentiation and population migration of Proteus mirabilis. Mol Microbiol 6, 1583-1591.

Altschul, S. F., Madden, T. L., Schaffer, A. A., Zhang, J., Zhang, Z., Miller, W. \& Lipman, J. (1997). Gapped BLAST and PSI-BLAST: a new generation of protein database search programs. Nucleic Acids Res 25, 3389-3402. 
Arantes, O. \& Lereclus, D. (1991). Construction of cloning vectors for Bacillus thuringiensis. Gene 108, 115-119.

Aravind, L. \& Koonin, E. V. (1998). The HD domain defines a new superfamily of metal-dependent phosphohydrolases. Trends Biochem Sci 23, 469-472.

Belas, M. R. \& Colwell, R. R. (1982). Adsorption kinetics of laterally and polarly flagellated Vibrio. J Bacteriol 151, 1568-1580.

Callegan, M. C., Novosad, B. D., Ramirez, R., Ghelardi, E. \& Senesi, S. (2006). Role of swarming migration in the pathogenesis of Bacillus endophthalmitis. Invest Ophthalmol Vis Sci 47, 4461-4467.

Chen, Z. W., Hassan-Abdulah, A., Zhao, G., Jorns, M. S. \& Mathews, F. S. (2006). Heterotetrameric sarcosine oxidase: structure of a diflavin metalloenzyme at $1.85 \AA$ resolution. J Mol Biol 360, 10001018.

Chin-A-Woeng, T. F. C., Bloemberg, G. V. \& Lugtenberg, B. J. J. (2003). Phenazines and their role in biocontrol by Pseudomonas bacteria. New Phytol 157, 503-523.

Cho, Y. H., Lee, E. J. \& Roe, J. H. (2000). A developmentally regulated catalase required for proper differentiation and osmoprotection of Streptomyces coelicolor. Mol Microbiol 35, 150-160.

Chugani, S. A., Whiteley, M., Lee, K. M., D’Argenio, D., Manoil, C. \& Greenberg, E. P. (2001). QscR, a modulator of quorum-sensing signal synthesis and virulence in Pseudomonas aeruginosa. Proc Natl Acad Sci U S A 98, 2752-2757.

Dick, H., Murray, R. G. \& Walmsley, S. (1985). Swarmer cell differentiation of Proteus mirabilis in fluid media. Can J Microbiol 31, 1041-1050.

Douglas, C. W. \& Bisset, K. A. (1976). Development of concentric zones in the Proteus swarm colony. J Med Microbiol 9, 497-500.

Engelmann, S., Lindner, C. \& Hecker, M. (1995). Cloning, nucleotide sequence, and regulation of katE encoding a sigma B-dependent catalase in Bacillus subtilis. J Bacteriol 177, 5598-5605.

Fraser, G. M. \& Hughes, C. (1999). Swarming motility. Curr Opin Microbiol 2, 630-635.

Ghelardi, E., Celandroni, F., Salvetti, S., Beecher, D. J., Gominet, M., Lereclus, D., Wong, A. C. L. \& Senesi, S. (2002). Requirement of $f l h A$ for swarming differentiation, flagellin export, and secretion of virulence-associated proteins in Bacillus thuringiensis. J Bacteriol 184, 6424-6433.

Ghelardi, E., Celandroni, F., Salvetti, S., Ceragioli, M., Beecher, D. J., Senesi, S. \& Wong, A. C. L. (2007). Swarming behavior and hemolysin BL secretion in Bacillus cereus. Appl Environ Microbiol 73, 4089-4093.

Gominet, M., Slamti, L., Gilois, N., Rose, M. \& Lereclus, D. (2001). Oligopeptide permease is required for expression of the Bacillus thuringiensis plcR regulon and for virulence. Mol Microbiol 40, 963-975.

Harshey, R. M. (2003). Bacterial motility on a surface: many ways to a common goal. Annu Rev Microbiol 57, 249-273.

Harshey, R. M. \& Matsuyama, T. (1994). Dimorphic transition in Escherichia coli and Salmonella typhimurium: surface-induced differentiation into hyperflagellate swarmer cells. Proc Natl Acad Sci U S A 91, 8631-8635.

Hsueh, Y. H., Somers, E. B., Lereclus, D., Ghelardi, E. \& Wong, A. C. L. (2007). Biosurfactant production and surface translocation are regulated by PlcR in Bacillus cereus ATCC 14579 under low-nutrient conditions. Appl Environ Microbiol 73, 7225-7231.

Kaiser, D. (2007). Bacterial swarming: a re-examination of cellmovement patterns. Curr Biol 17, R561-R570.

Kearns, D. B., Chu, F., Rudner, R. \& Losick, R. (2004). Genes governing swarming in Bacillus subtilis and evidence for a phase variation mechanism controlling surface motility. Mol Microbiol 52, 357-369.

Kim, W. \& Surette, M. G. (2004). Metabolic differentiation in actively swarming Salmonella. Mol Microbiol 54, 702-714.

Kim, Y., Lew, C. M. \& Gralla, J. D. (2006). Escherichia coli $p f s$ transcription: regulation and proposed roles in autoinducer-2 synthesis and purine excretion. J Bacteriol 188, 7457-7463.

Kirov, S. M., Castrisios, M. \& Shaw, J. G. (2004). Aeromonas flagella (polar and lateral) are enterocyte adhesins that contribute to biofilm formation on surfaces. Infect Immun 72, 1939-1945.

Köhler, T., Curty, L. K., Barja, F., van Delden, C. \& Pechère, J. C. (2000). Swarming of Pseudomonas aeruginosa is dependent on cell-tocell signaling and requires flagella and pili. J Bacteriol 182, 5990-5996.

Koyama, Y., Yamamoto-Otake, H., Suzuki, M. \& Nakano, E. (1991). Cloning and expression of the sarcosine oxidase gene from Bacillus sp. NS-129 in Escherichia coli. Agric Biol Chem 55, 1259-1263.

Lereclus, D., Arantes, O., Chaufaux, J. \& Lecadet, M. M. (1989). Transformation and expression of a cloned delta-endotoxin gene in Bacillus thuringiensis. FEMS Microbiol Lett 51, 211-217.

Liu, J. H., Lai, M. J., Ang, S., Shu, J. C., Soo, P. C., Horng, Y. T., Yi, W. C., Lai, H. C., Luh, K. T. \& other authors (2000). Role of $f l h D C$ in the expression of the nuclease gene $n u c A$, cell division and flagellar synthesis in Serratia marcescens. J Biomed Sci 7, 475-483.

Lucht, J. M. \& Bremer, E. (1994). Adaptation of Escherichia coli to high osmolarity environments: osmoregulation of the high-affinity glycine betaine transport system ProU. FEMS Microbiol Rev 14, 3-20.

Macfarlane, S., Hopkins, M. J. \& Macfarlane, G. T. (2001). Toxin synthesis and mucin breakdown are related to swarming phenomenon in Clostridium septicum. Infect Immun 69, 1120-1126.

Maddula, V. S. R. K., Pierson, E. A. \& Pierson, L. S., III (2008). Altering the ratio of phenazines in Pseudomonas chlororaphis (aureofaciens) strain 30-84: effects on biofilm formation and pathogen inhibition. J Bacteriol 190, 2759-2766.

Mariconda, S., Wang, Q. \& Harshey, R. M. (2006). A mechanical role for the chemotaxis system in swarming motility. Mol Microbiol 60, $1590-1602$.

Meury, J. (1988). Glycine betaine reverses the effects of osmotic stress on DNA replication and cellular division in Escherichia coli. Arch Microbiol 149, 232-239.

Østerås, M., Boncompagni, E., Vincent, N., Poggi, M. C. \& Le Rudulier, D. (1998). Presence of a gene encoding choline sulfatase in Sinorhizobium meliloti bet operon: choline- $O$-sulfate is metabolized into glycine betaine. Proc Natl Acad Sci U S A 95, 11394-11399.

Price-Whelan, A., Dietrich, L. E. P. \& Newman, D. K. (2006). Rethinking "secondary" metabolism: physiological roles for phenazine antibiotics. Nat Chem Biol 2, 71-78.

Rasko, D. A., Altherr, M. R., Han, C. S. \& Ravel, J. (2005). Genomics of the Bacillus cereus group of organisms. FEMS Microbiol Rev 29, 303 329.

Rather, P. N. (2005). Swarmer cell differentiation in Proteus mirabilis. Environ Microbiol 7, 1065-1073.

Reimmann, C., Ginet, N., Michel, L., Keel, C., Michaux, P., Krishnapillaia, V., Zala, M., Heurlier, K., Triandafillu, K. \& other authors (2002). Genetically programmed autoinducer destruction reduces virulence gene expression and swarming motility in Pseudomonas aeruginosa PAO1. Microbiology 148, 923-932.

Salvetti, S., Ghelardi, E., Celandroni, F., Ceragioli, M., Giannessi, F. \& Senesi, S. (2007). FlhF, a SRP-like GTPase, is involved in the regulation of flagellar arrangement, motility behaviour, and protein secretion in Bacillus cereus. Microbiology 153, 2541-2552. 
Senesi, S., Celandroni, F., Salvetti, S., Beecher, D. J., Wong, A. C. L. \& Ghelardi, E. (2002). Swarming motility in Bacillus cereus and characterization of a fliY mutant impaired in swarm cell differentiation. Microbiology 148, 1785-1794.

Senesi, S., Ghelardi, E., Celandroni, F., Salvetti, S., Parisio, E. \& Galizzi, A. (2004). Surface-associated flagellum formation and swarming differentiation in Bacillus subtilis are controlled by the ifm locus. J Bacteriol 186, 1158-1164.

Shin, S. \& Park, C. (1995). Modulation of flagellar expression in Escherichia coli by acetyl phosphate and the osmoregulator OmpR. J Bacteriol 177, 4696-4702.

Smith, L. T., Pocard, J. A., Bernard, T. \& Le Rudulier, D. (1988). Osmotic control of glycine betaine biosynthesis and degradation in Rhizobium meliloti. J Bacteriol 170, 3142-3149.

Steinmetz, M. \& Richter, R. (1994). Easy cloning of mini-Tn 10 insertions from the Bacillus subtilis chromosome. J Bacteriol 176, 1761-1763.

Von Ossowski, I., Mulvey, M. R., Leco, P. A., Borys, A. \& Loewen, P. C. (1991). Nucleotide sequence of Escherichia coli katE, which encodes catalase HPII. J Bacteriol 173, 514-520.

Wang, Q., Frye, J. G., McClelland, M. \& Harshey, R. M. (2004). Gene expression patterns during swarming in Salmonella typhimurium: genes specific to surface growth and putative new motility and pathogenicity genes. Mol Microbiol 52, 169-187.

Wang, Q., Mariconda, S., Suzuky, A., McClelland, M. \& Harshey, R. M. (2006). Uncovering a large set of genes that affect surface motility in Salmonella enterica serovar Typhimurium. J Bacteriol 188, 7981-7984.

Wang, Y., Dai, Y., Zhang, Y., Hu, Y., Yang, B. \& Chen, S. (2007). Effect of quorum sensing autoinducer degradation gene on virulence and biofilm formation of Pseudomonas aeruginosa. Sci China C Life Sci 50, 385-391.

Weber, A., Kögl, S. A. \& Jung, K. (2006). Time-dependent proteome alterations under osmotic stress during aerobic and anaerobic growth in Escherichia coli. J Bacteriol 188, 7165-7175.

Wurgler, S. M. \& Richardson, C. C. (1993). DNA binding properties of the deoxyguanosine triphosphate triphosphohydrolase of Escherichia coli. J Biol Chem 268, 20046-20054.

Young, G. M., Smith, M. J., Minnich, S. A. \& Miller, V. L. (1999). The Yersinia enterocolitica motility master regulatory operon, flhDC, is required for flagellin production, swimming motility, and swarming motility. J Bacteriol 181, 2823-2833.

Edited by: T. Abee 